\title{
ЗВ'ЯЗКИ КОМП'ЮТЕРНО-ТОМОГРАФІЧНИХ ХАРАКТЕРИСТИК ЗУБНИХ ДУГ З ОДОНТОМЕТРИЧНИМИ Й КЕФАЛОМЕТРИЧНИМИ ПОКАЗНИКАМИ ДІВЧАТ-БРАХІЦЕФАЛІВ ІЗ ОРТОГНАТИЧНИМ ПРИКУСОМ
}

\begin{abstract}
Резюме. Для коректного моделювання форми зубної дуги необхідно встановити найінформативніші параметри зубів і голови, взаємопов'язані з нею.

Мета дослідження - провести аналіз кореляцій КТ-розмірів, необхідних для побудови коректної фрорми зубної дуги з одонтометричними й кесралометричними показниками дівчат-брахіцесралів із ортогнатичним прикусом.

Матеріали і методи. Дослідження проведено згідно з власне розробленою схемою за допомогою дентального конусно-променевого томографра Veraviewepocs 3D. Виконували вимірювання таких розмірів верхніх і нижніх різців, іклів, малих та перших великих кутніх зубів (відповідно МКЗ та ВКЗ): довжини зуба, довжини кореня у присінково-язиковій та мезіодистальній проекціях, мезіодистального і присінково-язикового розмірів коронки зуба, ширини дентинно-емалевої межі у мезіодистальному та присінково-язиковому напрямках. Також визначали трансверзальні розміри верхньої й нижньої щелеп і сагітальні характеристики зубної дуги та кефалометричні розміри. Аналіз кореляцій отриманих результатів у дівчат-брахіцесралів $(\mathrm{n}=26)$ проводили з використанням непараметричного метода Спірмена у ліцензійному статистичному пакеті Statistica 6.0.

Результати досліджень та їх обговорення. У дівчат-брахіцефралів із ортогнатичним прикусом встановлено 348 достовірних і середньої сили недостовірних зв'язків із 1116 можливих (31,2 \%, з яких 17,9 \% - недостовірних середньої сили) із параметрами зубної дуги у фронтальній площині (з них 6 - 0,5 \% прямих сильних; 132 - 11,8 \% прямих середньої сили; 181 - 16,2 \% недостовірних прямих середньої сили; 10 - 0,9 \% зворотних середньої сили; $19-1,7$ \% недостовірних зворотних середньої сили); 79 зв'язків із 279 можливих (28,3 \%, з яких 14,3 \% недостовірних середньої сили) із параметрами верхньощелепної зубної дуги в сагітальній площині (з них 3 - 1,1 \% прямих сильних; 34 - 12,2 \% прямих середньої сили; 35 - 12,5 \% недостовірних прямих середньої сили; 2 - 0,7 \% зворотних середньої сили; 5 - 1,8 \% недостовірних зворотних середньої сили); 88 зв'язків із 279 можливих (31,5 \%, з яких 12,9 \% недостовірних середньої сили) із параметрами верхньощелепної зубної дуги у вертикальній площині (з них 2 - 0,7 \% прямих сильних; 50 - 17,9 \% прямих середньої сили; 36 - 12,9 \% недостовірних прямих середньої сили).

Висновки. У дівчат-брахіцефалів в усіх групах достовірні й середньої сили недостовірні кореляції лінійних розмірів, необхідних для побудови коректної форми зубної дуги з розмірами зубів та кефралометричними показниками, мають майже однаковий відсоток - 31,2 \% із трансверзальними розмірами верхньої і нижньої щелеп; 28,3 \% з параметрами верхньощелепної зубної дуги в сагітальній площині та 31,5 \% з параметрами верхньощелепної зубної дуги у вертикальній площині. Відносну більшість достовірних і середньої сили недостовірних кореляцій трансверзальних розмірів верхньої і нижньої щелеп у дівчат-брахіцефралів встановлено з присінково-язиковими розмірами коронок зубів $(34,7 \%)$, з довжиною зубів (44,2 \%) та 3 шириною дентинно-емалевої межі у мезіодистальному напрямку (30,6 \%). Більшість кореляцій параметрів верхньощелепної зубної дуги в сагітальній площині у дівчат-брахіцефралів встановлено з мезіодистальними розмірами коронок зубів (55,6 \%), 3 шириною дентинно-емалевої межі у мезіодистальному $(55,6 \%)$ і присінково-язиковому $(38,9 \%)$ напрямках та з довжиною кореня у присінково-язиковій (44,4 \%) і мезіодистальній (38,9 \%) проекціях; а параметрів верхньощелепної зубної дуги у вертикальній площині - 3 мезіодистальними (52,8 \%) і присінково-язиковими $(63,9 \%)$ розмірами коронок зубів та 3 шириною дентинноемалевої межі у присінково-язиковому напрямку $(44,4 \%)$.
\end{abstract}

Ключові слова: дівчата-брахіцефали з ортогнатичним прикусом; кореляції; метричні характеристики зубної дуги; одонтометричні показники; кефалометричні показники.

ВстУп У багатьох наукових дослідженнях доведено, що урахування розмірів зубних дуг в пропорційно-ієрархічному зв'язку з одонто-кесралометричними параметрами є актуальним питанням етнічної антропології, клінічної анатомії, косметології, щелепно-лицьової хірургії і судової медицини [2, 3, 5].

У кожної людини форма зубного ряду строго індивідуальна, тому прийнята за норму форма зубних рядів (на верхній щелепі-напівеліпса, на нижній щелепі - параболи) в ортодонтії тільки приблизна. У зв'язку з цим, ще з минулого століття науковці намагаються визначити ідеальну форму зубної дуги, керуючись ідеєю про її симетричність і підпорядкованість математичним закономірностям, представляючи форму дуги у вигляді алгебраїчних або геометричних фрормул [4, 8]. Однак для коректного моделювання необхідно оцінити не безліч кількісних показників, а встановити найіндрормативніші взаємопов'язані параметри [11].

У світовій літературі все частіше з'являються дослідження, в яких значну увагу приділяють вивченню зв'язків типів голови й обличчя із одонтометричними показниками, а також розмірами і формою зубних дуг [10, 13], однак подібних досліджень у представників юнацького віку із ортогнатичним прикусом не проводилось.
Метою дослідження було провести аналіз кореляцій КТ-розмірів, необхідних для побудови коректної фрорми зубної дуги з одонтометричними й кесралометричними показниками дівчат-брахіцесралів із ортогнатичним прикусом.

МАТЕРІАЛИ I МЕТОДИ Первинні показникИ розмірів зубів та голови дівчат Поділля з ортогнатичним прикусом ( $n=50$, визначали за 11 пунктами за М. Г. Бушан та співавт. [7]), отримані з банку даних науково-дослідного центру Вінницького національного медичного університету імені М. І. Пирогова у рамках договору про творче співробітництво між Вінницьким національним медичним університетом імені М. І. Пирогова та ВДНЗУ "Українська медична стоматологічна академія" (договір № 1 від 05.01.2015).

Дослідження проведено згідно з власне розробленою схемою [12] за допомогою дентального конусно-променевого томографра Veraviewepocs 3D. Проводили вимірювання таких розмірів верхніх і нижніх різців, іклів, МКЗ та перших ВКЗ: довжини зуба, довжини кореня у присінково-язиковій та мезіодистальній проекціях, мезіодистального і присінково-язикового розмірів коронки зуба, ширини дентинно-емалевої межі у мезіодистальному та присінково-язиковому напрямках. Оскільки в попередніх 
дослідженнях при порівнянні КТ-розмірів однойменних зубів правого і лівого боків достовірних або тенденцій відмінностей виявлено не було, тому ми в подальших дослідженнях використовували середні значення відповідних зубів на верхній та нижній щелепах [9].

Визначали наступні трансверзальні розміри верхньої й нижньої щелеп і сагітальні характеристики зубної дуги: відстань між верхівками піднебінних коренів верхніх перших ВКЗ; відстань між верхівками дистальних коренів верхніх перших ВКЗ; відстань між верхівками медіальних коренів верхніх перших ВКЗ; відстань між верхівками медіальних коренів нижніх перших ВКЗ; відстань між верхівками дистальних коренів нижніх перших ВКЗ; відстань між горбками іклів верхньої щелепи; відстань між верхівками коренів іклів верхньої щелепи; відстань між горбками іклів нижньої щелепи; відстань між верхівками коренів іклів нижньої щелепи; відстань між точками Пона на верхніх перших ВКЗ; відстань між точками Пона на верхніх перших МК3; відстань між вестибулярними медіальними буграми перших ВКЗ; іклова сагітальна відстань верхньої щелепи; премолярна сагітальна відстань верхньої щелепи; молярна сагітальна відстань верхньої щелепи; глибина піднебіння на рівні іклів; глибина піднебіння на рівні перших МКЗ; глибина піднебіння на рівні перших ВКЗ.

Визначали наступні кефалометричні розміри [1]: сагітальну дугу, поперечну дугу, найбільший обхват голови, проекційна відстань від маківки голови (vertex) до верхнього краю слухового отвору, найбільші довжину та ширину голови, найменшу ширину голови, середню ширину обличчя, ширину обличчя, зовнішньоочну ширину, міжочноямкову ширину, ширину основи носа, ширину ротової щілини, вушний діаметр, висоту лоба, фрізіологічну довжину обличчя, довжину носа, висоту носа, глибину носа, висоту верхньої частини обличчя, відстань між назіон та міжрізцевою точкою, відстань між назіон та простіон, морфологічну довжину обличчя, висоту верхньої губи, висоту нижньої губи і нижньої частини обличчя і червоної облямівки губ, ширину нижньої щелепи, довжину тіла нижньої щелепи, відстань від аурикулярної точки до підборіддя, відстань від аурикулярної точки до кута нижньої щелепи, відстань від аурикулярної точки до глабели, відстань від аурикулярної точки до назіон, відстань від аурикулярної точки до субназіон, відстань від аурикулярної точки до міжрізцевої точки.

Аналіз кореляцій отриманих результатів у дівчат-брахіцесралів ( $\mathrm{n}=26)$ проводили з використанням непараметричного методу Спірмена у ліцензійному статистичному пакеті Statistica 6.0.

РЕЗУЛЬТАТИ ДОСЛІДЖЕНЬ ТА ЇХ ОБГОВОРЕННЯ При аналізі особливостей достовірних і середньої сили недостовірних кореляцій трансверзальних розмірів верхньої й нижньої щелеп та сагітальних характеристик зубної дуги з одонтометричними і кефалометричними показниками дівчат-брахіцефалів із ортогнатичним прикусом встановлено наступні множинні зв'язки: прямі, переважно середньої сили, достовірні (r від 0,43 до 0,49) і недостовірні (r від 0,30 до 0,39) зв'язки відстаней між верхівками дистальних коренів верхніх перших ВКЗ та між верхівками медіальних і дистальних коренів нижніх перших ВКЗ із майже з половиною мезіодистальних розмірів коронок зубів; прямі, переважно середньої сили достовірні (r від 0,39 до 0,56) і недостовірні середньої сили (r від 0,30 до 0,37) зв'язки відстані між горбками іклів верхньої щелепи з більшістю мезіодистальних і присінково-язикових розмірів коронок зубів та з половиною показників довжини зубів і довжини кореня у присінковоязиковій проекції; прямі, переважно середньої сили достовірні (r від 0,39 до 0,55) і недостовірні середньої сили ( $r$ від 0,30 до 0,38) зв'язки відстані між верхівками дистальних коренів верхніх перших ВКЗ із усіма присінковоязиковими розмірів коронок зубів верхньої щелепи та між верхівками медіальних і дистальних коренів нижніх перших ВКЗ, між точками Пона на верхніх перших ВКЗ, між вестибулярними медіальними буграми перших ВКЗ і між горбками іклів нижньої щелепи з більшістю присінково-язикових розмірів коронок зубів нижньої щелепи; прямі, переважно середньої сили достовірні (r від 0,40 до 0,57) і недостовірні середньої сили ( $r$ від 0,30 до 0,37) зв'язки між верхівками медіальних і дистальних коренів нижніх перших ВКЗ, між точками Пона на верхніх перших ВК3, між вестибулярними медіальними буграми перших ВК3, між верхівками коренів іклів верхньої щелепи і між горбками іклів нижньої щелепи з більшістю показників довжини зубів; зворотні середньої сили достовірні (r від $-0,40$ до -0,59) і недостовірні середньої сили ( $r$ від -0,31 до -0,37) зв'язки між більшістю трансверзальних розмірів верхньої і нижньої щелеп (за винятком відстаней між верхівками піднебінних коренів верхніх перших ВКЗ, між верхівками дистальних і медіальних коренів верхніх перших ВКЗ та між горбками іклів нижньої щелепи) із шириною дентинно-емалевої межі у мезіодистальному напрямку нижніх іклів; прямі, переважно середньої сили достовірні (r від 0,44 до 0,58) і недостовірні зв'язки середньої сили ( $r$ від 0,30 до 0,36) відстаней між верхівками медіальних і дистальних коренів нижніх перших ВКЗ із більшістю показників ширини дентинно-емалевої межі у присінково-язиковому напрямку різців й іклів нижньої щелепи та між точками Пона на верхніх перших ВКЗ і МК3, між вестибулярними медіальними буграми перших ВК3 і між горбками іклів верхньої і нижньої щелеп із показниками ширини дентинно-емалевої межі у присінковоязиковому напрямку латеральних різців верхньої і нижньої щелеп; прямі, переважно недостовірні середньої сили (r від 0,30 до 0,38) зв'язки відстаней між верхівками коренів іклів верхньої щелепи і між горбками іклів нижньої щелепи з половиною показників довжини кореня різців й іклів у мезіодистальній проекції; прямі середньої сили достовірні (r від 0,39 до 0,57) і недостовірні зв'язки середньої сили (r від 0,31 до 0,38) між більшістю трансверзальних розмірів верхньої і нижньої щелеп із сагітальною дугою (за винятком відстаней між верхівками піднебінних коренів верхніх перших ВКЗ та між верхівками коренів іклів верхньої щелепи) і найбільшою довжиною голови (за винятком відстаней між верхівками піднебінних коренів верхніх перших ВКЗ, між верхівками дистальних коренів нижніх перших ВКЗ та між верхівками коренів іклів верхньої щелепи); прямі середньої сили достовірні (r від 0,39 до 0,48) і недостовірні середньої сили ( $r$ від 0,30 до $0,38)$ зв'язки відстаней між верхівками дистальних і медіальних коренів верхніх перших ВКЗ та між точками Пона на верхніх перших МКЗ з більшістю широтних розмірів обличчя, а також лише між верхівками дистальних коренів верхніх перших ВКЗ із більшістю висотних розмірів обличчя; зворотні середньої сили недостовірні (r від -0,32 до -0,37) зв'язки відстані між верхівками дистальних коренів нижніх перших ВКЗ із більшістю висотних розмірів обличчя; прямі середньої сили достовірні (r від 0,39 до 
0,54) і недостовірні зв'язки середньої сили (r від 0,30 до 0,37 ) відстаней між верхівками дистальних коренів верхніх перших ВКЗ, між горбками іклів верхньої щелепи і між верхівками коренів іклів верхньої та нижньої щелеп 3 практично усіма показниками відстаней від аурикулярної точки до відповідних точок на черепі; прямі, переважно середньої сили, достовірні (r від 0,39 до 0,57) і недостовірні середньої сили (r від 0,30 до 0,39) зв'язки усіх параметрів верхньощелепної зубної дуги в сагітальній площині з більшістю мезіодистальних розмірів коронок зубів, показників довжини різців верхньої щелепи, шириною дентинно-емалевої межі у мезіодистальному напрямку різців верхньої і нижньої щелеп, довжиною кореня різців верхньої щелепи у присінково-язиковій проекції та довжиною кореня різців нижньої щелепи у мезіодистальній проекції, а також лише премолярної і молярної сагітальних відстаней верхньої щелепи з більшістю показників ширини дентинно-емалевої межі у присінково-язиковому напрямку; прямі, переважно достовірні, середньої сили ( $r$ від 0,40 до 0,55) зв'язки усіх параметрів верхньощелепної зубної дуги у вертикальній площині з більш ніж половиною мезіодистальних та присінково-язикових розмірів коронок зубів; прямі, переважно достовірні, середньої сили ( $r$ від 0,40 до 0,52) зв'язки глибини піднебіння на рівні перших МКЗ і ВКЗ з більш ніж половиною показників ширини дентинно-емалевої межі у присінково-язиковому напрямку (переважно на верхній щелепі) та 3 майже третиною кефралометричних показників.

Враховуючі результати попередніх досліджень [6], необхідно відмітити, що у дівчат при розподілі на різні краніотипи зростає кількість достовірних і середньої сили недостовірних кореляцій із трансверзальними розмірами верхньої і нижньої щелеп (відповідно 18,7 \% в загальній групі, 31,2 \% - у брахіцесралів) та 3 параметрами верхньощелепної зубної дуги у вертикальній площині (відповідно 6,5 \% в загальній групі, 31,5 \% - у брахіцесралів) також переважно за рахунок середньої сили недостовір-

\section{СПИСОК ЛІТЕРАТУРИ}

1. Алексеев В. П. Краниометрия: методика антропологических исследований / В. П. Алексеев, Г. Ф. Дебец. - М. : Наука, 1964. $-128 \mathrm{c}$.

2. Влияние одонтометрических параметров на форму и размеры мезогнатических зубных дуг / Д. А. Доменюк, Э. Г. Ведешина, С. В. Дмитриенко [и др.] // Кубанский научный медицинский вестник. - 2015. - № 4. - С. 73-78.

3. Изменчивость параметров зубной дуги нижней челюсти у женщин с различными фрормами лица / Л. В. Музурова, М.В.Михеева, В.В.Коннов, С.Н.Шелудько // Бюллетень медицинских интернет-конореренций. - 2014. - Т. 4, № 6. - С. 937-939.

4. К вопросу о построении дуги Хаулея / С. В. Дмитриенко, Д. С. Дмитриенко, Н. Н. Климова [и др.] // Ортодонтия. - 2011. - T. 54, № 2. - С. 11-13.

5. К вопросу определения размеров зубных дуг в сагиттальном и трансверзальном направлениях / В. В. Бердин, А. В. Севастьянов, С. Б. Фищев [и др.]. Лепилин // Стоматология детского возраста и просрилактика. - 2013. - Вып. XII, Т. 46, № 3. - С. 43-45.

6. Марченко А. В. Кореляції лінійних розмірів, необхідних для побудови коректної форми зубної дуги з одонтометричними й кефалометричними показниками дівчат із ортогнатичним прикусом / А. В. Марченко // Вісник морфології. -2017. - Т. 23, № 2. - С. 273-278.

7. Справочник по ортодонтии / М. Г. Бушан, 3. С. Василенко, Л. П. Григорьева. - Кишенев : Картя Молдовеняскэ, 1990. - 488 с. них зв'язків (за винятком параметрів верхньощелепної зубної дуги у вертикальній площині в дівчат-брахіцесралів, у яких переважно за рахунок достовірних зв'язків); з параметрами верхньощелепної зубної дуги в сагітальній площині, навпаки кількість кореляцій зменшується (відповідно 33,3 \% в загальній групі, 28,3 \% - у брахіцефалів).

ВИСнОВки 1. У дівчат-брахіцефалів в усіх групах достовірні й середньої сили недостовірні кореляції лінійних розмірів, необхідних для побудови коректної форми зубної дуги з розмірами зубів та кефралометричними показниками, мають майже однаковий відсоток - 31,2 \% із трансверзальними розмірами верхньої і нижньої щелеп; 28,3 \% 3 параметрами верхньощелепної зубної дуги в сагітальній площині та 31,5 \% з параметрами верхньощелепної зубної дуги у вертикальній площині.

2. Відносну більшість достовірних і середньої сили недостовірних кореляцій трансверзальних розмірів верхньої і нижньої щелеп у дівчат-брахіцесралів встановлено з присінково-язиковими розмірами коронок зубів (34,7 \%), 3 довжиною зубів (44,2 \%) та 3 шириною дентинно-емалевої межі у мезіодистальному напрямку $(30,6$ \%).

3. Більшість кореляцій параметрів верхньощелепної зубної дуги в сагітальній площині у дівчат-брахіцефалів встановлено 3 мезіодистальними розмірами коронок зубів (55,6 \%), з шириною дентинно-емалевої межі у мезіодистальному (55,6 \%) і присінково-язиковому (38,9 \%) напрямках та з довжиною кореня у присінковоязиковій $(44,4$ \%) і мезіодистальній $(38,9$ \%) проекціях; а параметрів верхньощелепної зубної дуги у вертикальній площині - 3 мезіодистальними (52,8 \%) і присінково-язиковими (63,9 \%) розмірами коронок зубів та 3 шириною дентинно-емалевої межі у присінково-язиковому напрямку $(44,4 \%)$.

Перспективи подальших досліджень полягають у коректному моделюванні зубних дуг, що розширить можливості індивідуального підходу ортодонта при корекції їх форми.

8. A computerized analysis of the shape and stability of mandibular arch form / J. M. Felton, P. M. Sinclair, D. L. Jones, R. G. Alexander // Am. J. Orthod. Dentofacial Orthop. - 1987. - No. 92. - P. 478-483.

9. Computer-tomographic characteristics of root length incisors and canines of the upper and lower jaws in boys and girls with different craniotypes and physiological bite / A. V. Marchenko, I. V. Gunas, T. O. Petrushanko [et al.] // Wiadomości Lekarskie. 2017. - LXX(3, I). - P. 499-502.

10. Development of cephalometric norms using a unified facial and dental approach / G. Anderson, H. W. Fields, M. Beck [et al.] // The Angle Orthodontist. - 2006. - Vol. 76, No. 4. - P. 612-618.

11. Discriminant factor analysis of dental arch dimensions with 3-dimensional virtual models / M. Slaj, S. Spalj, D. Jelusic, M. Slaj // Am. J. Orthod. Dentofacial Orthop. - 2011. - Vol. 140, No. 5. - P. 680-687.

12. Gunas I. V. Methodological aspects of computed tomography odontomorphometry of boys and girls with the physiological bite I I. V. Gunas, N. A. Dmitriev, A. V. Marchenko // Journal of Education, Health and Sport. - 2015. - No. 5, Vol. 11. - P. 345-355.

13. Relation between anthropometric and cephalometric measurements and proportions of the face of healthy young white adult men and women / M. Budai, L. G. Farkas, B. Tompson // J. Craniofac. Surg. - 2003. - Vol. 14, No. 2. - P. 154-161.

Отримано 11.01 .18 


\section{CONNECTIONS OF COMPUTER-TOMOGRAPHIC CHARACTERISTICS OF DENTAL ARCHES WITH ODONTOMETRIC AND CEPHALOMETRIC INDICES OF BRACHYCEPHALIC GIRLS WITH ORTHOGNATHIC BITE}

Summary. For correct modeling of the shape of the dental arch, it is necessary to establish the most informative interrelated tooth parameters and the head.

The aim of the study - to carry out an analysis of the correlations of CT-sizes necessary for the construction of the correct form of the dental arch with odontometric and cephalometric characteristics of brachycephalic girls with orthognathic bite.

Materials and Metohods. The research was carried out in accordance with the self-developed scheme using the Veraviewepocs 3D dental cone beam. Measurements of the following sizes of upper and lower incisors, canines, small and first large angular teeth (respectively, SAT and LAT): length of the tooth, root length in vestibule-tongue and mesiodistal projections, mesiodistal and vestibuletongue sizes crowns of the tooth, width of dentine-enamel boundaries in mesiodistal and vestibule-tongue directions. Also, the transversal dimensions of the upper and lower jaw and sagittal characteristics of the dental arch and cephalometric dimensions were determined. The correlation analysis of the results obtained in girls-mesocephals $(n=26)$ was performed using the nonparametric Spirman method in the statistical package "Statistica 6.0".

Results and Discussion. In brachycephalic girls with orthognathic bite, 348 reliable and average strength of false connections were detected out of 1116 possible (31.2 \%, of which $17.9 \%$ of false median force) with dental arc parameters in the frontal plane (of which $6-0.5 \%$ of direct strong; $132-11.8 \%$ of direct average strength; $181-16.2 \%$ of false direct average forces; $10-0.9 \%$ of reciprocal average strength; $19-1.7 \%$ of unreliable reciprocal average forces); 79 out of 279 possible ( $28,3 \%$, of which $14,3 \%$ are unreliable average forces) with parameters of maxillary dental arches in the sagittal plane (of which $3-1.1 \%$ of direct strong; $34-12.2 \%$ direct average strength; 35 $-12.5 \%$ of false direct middle forces; $2-0.7 \%$ of reciprocal average strength; $5-1.8 \%$ of false reciprocal average forces); 88 out of 279 possible (31.5\%, of which $12.9 \%$ of the unreliable mean strength) with the parameters of the maxillary dental arch in the vertical plane (of which $2-0.7 \%$ of direct strong; $50-17.9 \%$ direct average strength; $36-12.9 \%$ of false direct middle forces).

Conclusions. 1. In brachycephalic girls, in all groups the reliable and average strength of the unreliable correlations of the linear sizes necessary for the correct form of the dental arch with dental size and cephalometric indices have almost the same percentage $-31.2 \%$ with transversal dimensions of the upper and lower jaw; $28.3 \%$ with parameters of maxillary dental arch in sagittal plane and $31.5 \%$ with parameters of maxillary dental arch in vertical plane. 2. Relative majority of reliable and average strength of inaccurate correlations of transversal dimensions of the upper and lower jaw in brachycephalic girls is established with the vestibule-tongue size of crowns of teeth (34.7\%), with teeth lengths (44.2\%) and with the width of dentin-enamel boundaries in the mesiodistal direction (30.6\%). 3. Most correlations of the parameters of the maxillary dental arch in the sagittal plane in brachycephalic girls are established with mesiodistal dimensions of crowns of teeth (55.6\%), with the width of the dentin-enamel border in the mesiodistal (55.6\%) and vestibule-tongue (38.9\%) directions and with the length of the root in the vestibule-tongue (44.4\%) and mesiodistal (38.9\%) projections; and the parameters of the maxillary dental arc in the vertical plane - with mesiodistal (52.8 \%) and vestibule-tongue (63.9\%) sizes of crowns of teeth and with the width of the dentin-enamel border in the vestibule-tongue direction (44.4 \%).

Key words: girls-brachycephals with orthognatic bite; correlations; metric characteristics of the dental arch; odontometric indicators; cephalometric indicators.

(ㄱ). В. Марченко

ВГУзУ “Украинская медицинская стоматологическая академия", г. Полтава

\section{СВЯЗИ КОМПЬЮТЕРНО-ТОМОГРАФИЧЕСКИХ ХАРАКТЕРИСТИК ЗУБНЫХ ДУГ С ОДОНТОМЕТРИЧЕСКИМИ И КЕФАЛОМЕТРИЧЕСКИМИ ПОКАЗАТЕЛЯМИ ДЕВУШЕК-БРАХИЦЕФАЛОВ С ОРТОГНАТИЧЕСКИМ ПРИКУСОМ}

Резюме. Для корректного моделирования формы зубной дуги необходимо установить наиболее информативные параметры зубов и головы, взаимосвязанные с ней.

Цель исследования - провести анализ корреляций КТ-размеров, необходимых для построения корректной формы зубной дуги с одонтометрическими и кефралометрическими показателями девушек-брахицефралов с ортогнатическим прикусом. Материалы и методы. Исследование проведено в соответствии с собственно разработанной схемой с помощью дентального конусно-лучевого томограсра Veraviewepocs 3D. Проводили измерения следующих размеров верхних и нижних резцов, клыков, малых и первых больших коренных зубов (соответственно МКЗ и БКЗ): длина зуба, длина корня в преддверно-языковой и мезиодистальной проекциях, мезиодистальный и преддверно-языковой размер коронки зуба, ширина дентино-эмалевой границы в мезиодистальном и преддверно-языковом направлениях. Также определяли трансверзальные размеры верхней и нижней челюстей и сагиттальные характеристики зубной дуги и кефалометрические размеры. Анализ корреляций полученных результатов у девушек-брахицефалов $(\mathrm{n}=26)$ проводили с использованием непараметрического метода Спирмена в лицензионном статистическом пакете Statistica 6.0.

Результаты исследований и их обсуждение. У девушек-брахицефалов с ортогнатическим прикусом установлено 348 достоверных и средней силы недостоверных связей из 1116 возможных (31,2 \%, из которых 17,9 \% - недостоверных средней силы) с параметрами зубной дуги во фронтальной плоскости (из них 6 - 0,5 \% прямых сильных; 132 - 11,8 \% прямых средней силы; 181 - 16,2 \% недостоверных прямых средней силы; 10 - 0,9 \% обратных средней силы; 19 - 1,7 \% недостоверных обратных средней силы; 79 связей из 279 возможных (28,3\%, из которых 14,3 \% недостоверных средней силы) с параметрами верхнечелюстной зубной дуги в сагиттальной плоскости (из них 3 - 1,1 \% прямых сильных; 34 - 12,2 \% прямых средней силы; 35 - 12,5 \% недостоверных прямых средней силы; 2- 0,7 \% обратных средней силы; 5- 1,8 \% недостоверных обратных средней силы); 88 связей из 279 возможных (31,5\%, из которых 12,9 \% недостоверных средней силы) с параметрами верхнечелюстной зубной дуги в вертикальной плоскости (из них 2 - 0,7 \% прямых сильных; 50 - 17,9 \% прямых средней силы; 36 - 12,9 \% недостоверных прямых средней силы).

Выводы. У девушек-брахицефалов во всех группах достоверные и средней силы недостоверные корреляции линейных размеров, необходимых для построения корректной формы зубной дуги с размерами зубов и кесралометрическими показа- 
телями, имеют почти одинаковый процент - 31,2 \% с трансверзальными размерами верхней и нижней челюстей; 28,3 \% с параметрами верхнечелюстной зубной дуги в сагиттальной плоскости и 31,5% с параметрами верхнечелюстной зубной дуги в вертикальной плоскости. Относительное большинство достоверных и средней силы недостоверных корреляций трансверзальных размеров верхней и нижней челюстей у девушек-брахицефалов установлена с преддверно-языковыми размерами коронок зубов (34,7 \%), с длиной зубов (44,2 \%) и с шириной дентино-эмалевой границы в мезиодистальном направлении (30,6 \%). Большинство корреляций параметров верхнечелюстной зубной дуги в сагиттальной плоскости у девушекбрахицефалов установлена с мезиодистальными размерами коронок зубов (55,6 \%), с шириной дентинно-эмалевой границы в мезиодистальном (55,6 \%) и преддверно-языковом (38,9\%) направлениях и с длиной корня в преддверно-языковой (44,4 \%) и мезиодистальной (38,9 \%) проекциях; а параметров верхнечелюстной зубной дуги в вертикальной плоскости - с мезиодистальными (52,8 \%) и преддверно-языковыми (63,9 \%) размерами коронок зубов и с шириной дентино-эмалевой границы в преддверно-языковом направлении (44,4 \%).

Ключевые слова: девушки-брахицефралы с ортогнатическим прикусом; корреляции; метрические характеристики зубной дуги; одонтометрические показатели; кефалометрические показатели. 